\title{
INVESTIGATIONS OF OIL POLLUTION WITH ELECTRICAL PROSPECTING METHODS
}

\author{
Modin I.N., Shevnin V.A., Bobatchev A.A., Bolshakov D.K., Leonov D.A., Vladov M.L. \\ Moscow state university \\ Russia, 119899, Moscow, MSU Faculty of Geology, fax: (+7-095)-9394963 \\ E-mail: sh@geophys.geol.msu.su
}

The most widespread source of pollution in Russia is the oil pollution. It occurs at all stages of oil production, transportation and processing. Outflows, proceeding during decades result to formation of oil secondary deposits. In a near-surface zone, oil pollution becomes especially chemically active and reacts with geological environment, that results in the anomalies of various geophysical methods: SP, IP, GPR and resistivity. The oil pollution is an unusual object due to its ability to oxidation and mobility. The pollution causes processes, occurring with the speed, differed from natural geological processes. Changes of rock properties, caused by oil pollution are inconsistent. A priory, for example, the oil is an isolator, but frequently it causes anomalies of lowered resistivity.
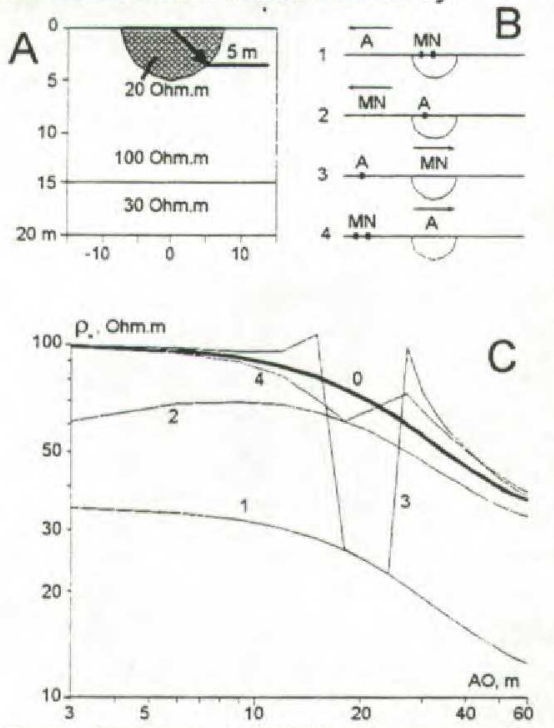

Fig. 1. Example of NSI (A), types of survey (B) and sounding curves ( C)



Fig.2. The scheme of nonconformable distorting effect's origin for pole-dipole array.
For engineering and environmental studies with electrical methods in urban areas (including pollution studies) the main problem is the influence of geological noise. Upper part of cross-section includes many near-surface inhomogeneities (NSI), caused with artificial ground, asphalt cover, trenches, cables, tubes, etc. These inhomogeneities create strong distortions and influence like "the broken glass", preventing from clear seeing deep objects. NSI distorting influence can be canceled by the application of total electric sounding (TES) technology, developed in MSU. In TES technology we apply two-sided pole-dipole array with step of distance growth equal to step between VES sites along profile. NSI creates distortions of four different types (fig.1C), when movable (single or dipole) element crosses the NSI, or unmovable (single or dipole) element is placed in NSI limits (fig.1B). Some distortions of sounding curves are conformable (fig.1C, 1-2), whereas others are non-conformable (fig. 1C, 3-4). On apparent resistivity cross-section distortions display as vertical and inclined strip zones (fig. 2,3). For different types of array (Pole-dipole, pole-pole, Schlumberger, Wenner, dipole-dipole, etc.) distortions are different (fig.3). For several NSI (fig.3, 3) interference of distortions appears. We developed software for canceling such distortions. The algorithm of median polishing was offered by J.W.Tukey (1981), and after modification made by E.V.Pervago was applied for processing of Total Electrical Sounding (TES) data. The algorithm's operation is based on regularity of distortion effects and it allows to cancel ef-

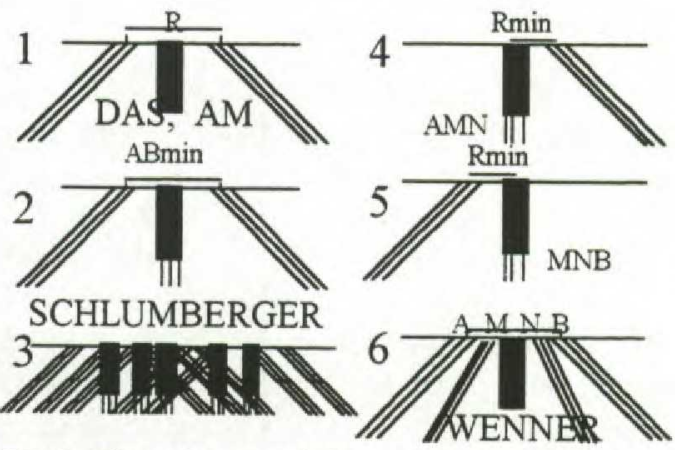

Fig. 3. The schemes of distorting effects appearance on $\rho_{\mathrm{a}}$ cross-sections for different arrays. 
fectively these effects on apparent resistivity pseudo-cross-section. J.W.Tukey described processing algorithm for data, given in the table as following: at the first step - counting and subtracting median value for each column; at the second step - counting and subtracting median value for every row. Then the 1st and 2nd steps

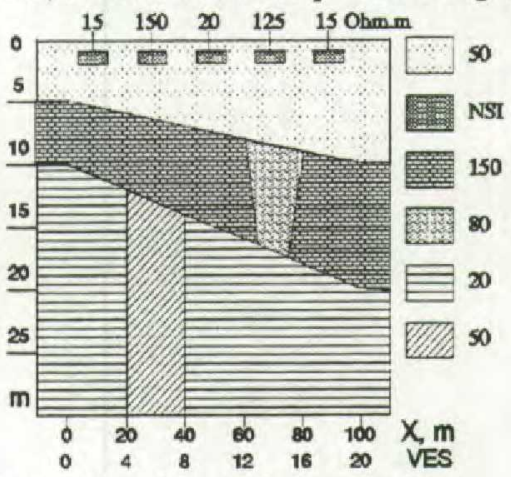

Fig.4. Geoelectrical model with layering, deep objects and NSI.

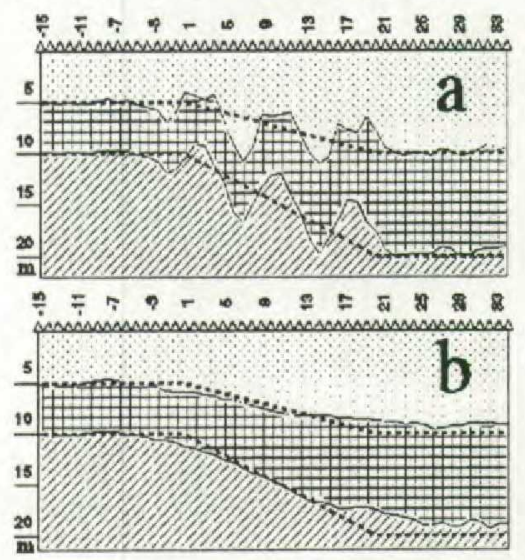

Fig.5. Interpretation results for the model from fig. 4 with filtering geological noise (b) and without it (a). 3 . Fitting error, \%

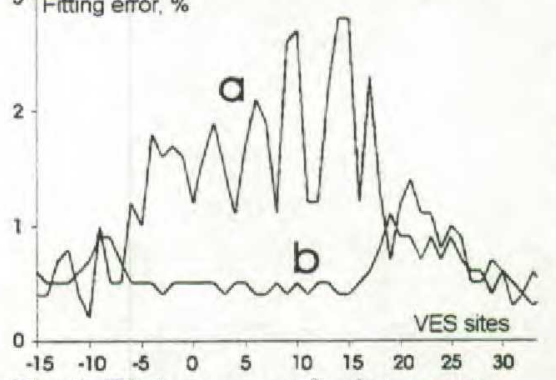
Fig.6. Fitting errors for interpretation results from fig. 5 with filtering geological noise (b) and without it (a).

absent. Thus, maximal distance for frequency-independent area is the function of the earth resistivity and working frequency. (it is determined by the near zone condition). On frequency $625 \mathrm{~Hz}$ for example, when $\rho=1$ Ohm.m, this zone limit is at $r=10 \mathrm{~m}$, when $\rho=10 \mathrm{Ohm} . \mathrm{m}$, it exist up to $\mathrm{r}=32 \mathrm{~m}$, when $\rho=100 \mathrm{Ohm} . \mathrm{m}, \mathrm{r}=100 \mathrm{~m}$. 2. In practice non-contact survey is similar to EM methods with their simplicity in field operations. Electrical sounding results shown on fig. $9-10$ were measured with non-contact resistivity technology.

Ecological studies of oil pollution on the department of geophysics MSU were carried out for several years, including town Noginsk (1993), on oil refining factories in Moscow (1994), Novokujbishevsk (1994-96) and Syzrany (1995-96). The depth of polluted zone was from 0.5 up to $50 \mathrm{~m}$ and the time of its formations from several months till 50 years. A typical example is the Moscow oil refining factory in Kapotnya.

On the factory in Kapotnya oil polluted zone is placed at the depth of several meters. For its study a complex of methods VES, SP, IP, GPR was applied (fig.7). A geological situation is typical for Moscow region. 
On depth about $10 \mathrm{~m}$ the waterproof layer of Jurassic clay is situated, and higher of it is sand, the lower part of which is filled with water. The groundwater level is on the depth about $1.5 \mathrm{~m}$. On that boundary the oil pollution is placed, being existed constantly for a long time. The top part of a cross-section with the thickness of $2-3 \mathrm{~m}$ is an artificial ground, which is typical for urban areas and has extremely changeable properties. Just in this layer several anomalous zones with intensive oil pollution are located. These zones are confidently mapped on IP, SP, GPR and resistivity methods' data. Polluted object is appeared similar to ore body, because it shows low resistivity, negative SP potential, high IP response. GPR shows low dielectric parameters

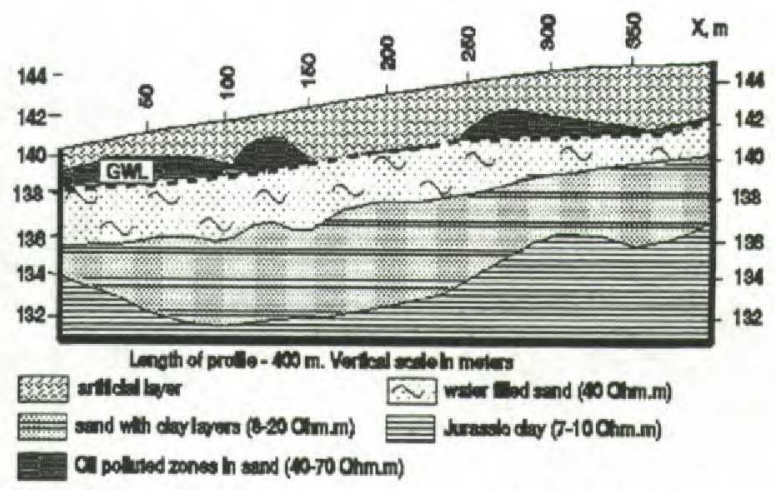

Fig.7. Results of electrical survey above shallowdepth oil pollution in Kapotnja. in polluted area.

Such low-resistive anomalies in the areas of oil pollution were found also by H.Vanhala (Finland)(1994, 1997). Why does oil pollution seem to be low resistive object? In accordance with investigations some scientists: Bailey N.J.L. (1973,1981), Evans C.R. (1977,1981), Rogers M.A. (1973, 1977), Dostalek M. (1975) oil-transforming bacteria are probably responsible for that. In upper part of the cross-section bacteria are very active, they transform upper layer of the oil film into some acids. Acids react with rocks and iron ions in water and result in high groundwater conductivity, karst processes and pyrite creation. Pyrite gives increased IP response.

The GPR data were interpreted independently, and other methods -- in integration. The GPR data only after processing were possible to reveal layered structure and the sites of pollution. The total electrical sounding - TES was used as a structural method for tracing groundwater level (GWL) and a clayey basement. With the help of an integrated parameter of pollution it became possible to find out its distribution in the area and on the depth. We used a priory information about the thickness and exact places of pollution at the reference profile. To characterize pollution we applied such parameters like the relative thickness of a polluted layer and its bottom's depth. These values were estimated on the regression dependence between these two parameters and some anomalous values of the measured geophysical fields and their dispersions (fig.8). For localization of pollution in plan IP method gave the maximum contribution, about $80 \%$ of the all information. SP and resistivity gave less information. GPR information gave wider polluted areas than geological data. We suppose that GPR could see the whole area of pollution whereas the direct geo-

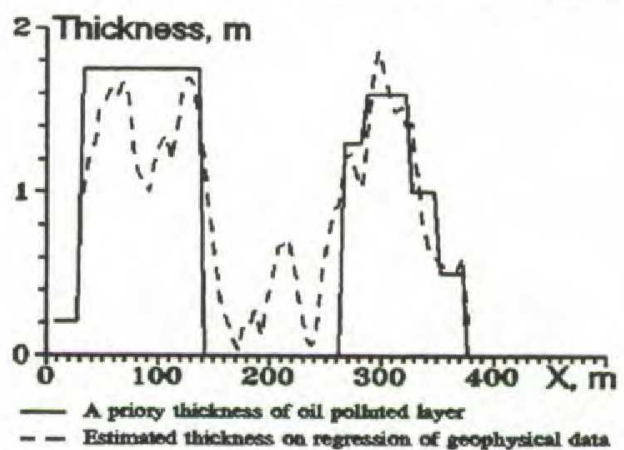

Fig.8. Results of polluted layer thickness estimation on regression with geophysical data. logical methods could see only the strongest pollution.

In Novokujbishevsk the study of territory around the oil refining factory was carried out for estimating ecological consequences of this factory activity. In upper part of a geological cross-section on depths up to $50 \mathrm{~m}$ during several decades of factory activity in the result of oil leakage from pipelines and storehouses the signifi-

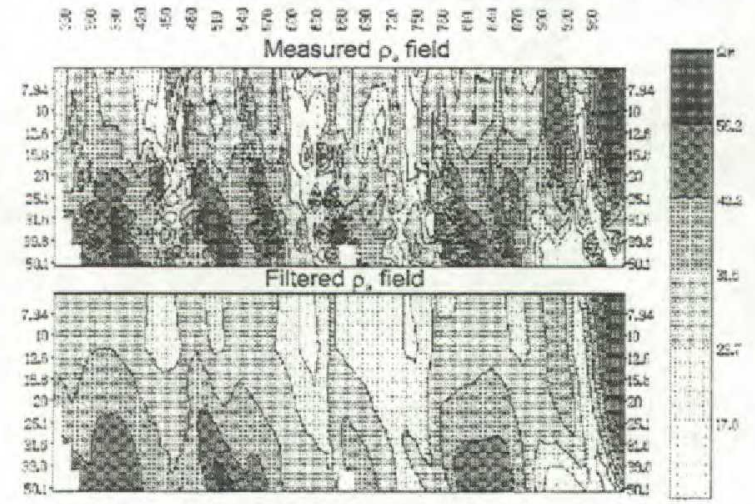

Fig.9. Novokujbishevsk, $p_{\mathrm{a}}$ field measured with noncontact electrical sounding technology before and after canceling geological noise

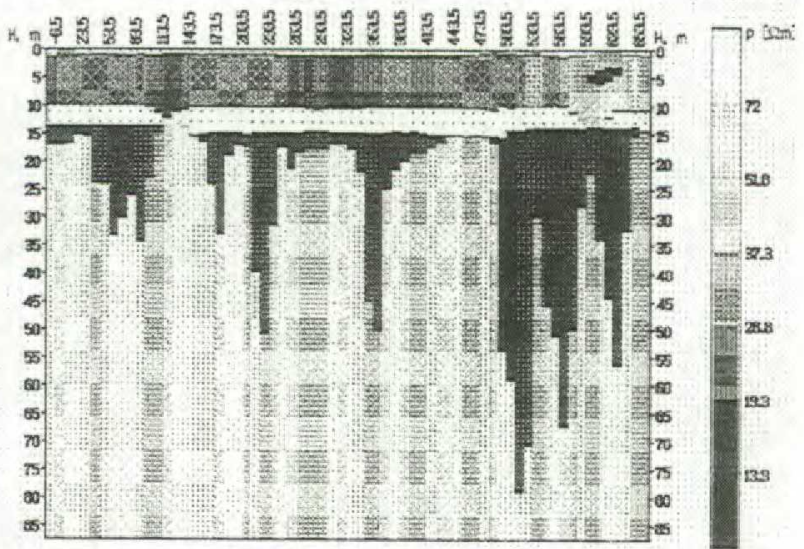

Fig. 10. Results of TES interpretation with low resistive traces of oil pollution for data from fig.9. 
cant amount of oil products was collected. That can be considered as a rich secondary oil deposit. The pollution spread to significant distance (several $\mathrm{km}$ ), despite extremely low values of rock permeability.

The geophysical study in Novokujbishevsk was carried out by VES in several stages due to great area for investigation. Each stage included several VES profiles with about 200 VES sites measured on TES (the total electrical sounding) technology with canceling geological noise. The study of the area (taking into account a priory data and results of drilling) has allowed to reveal layered structure of a cross-section and to find out paleovalleys, filled with loose deposits. The system of such paleovalleys serves the most probable ways of oil pollution

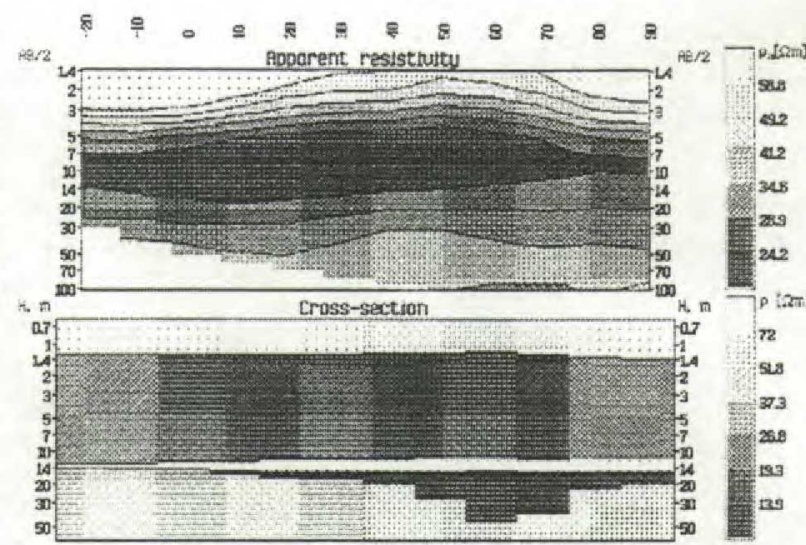

Fig.11. Results of TES interpretation over zone of oil pollution, Novokujbishevsk, profile 13 spreading at significant distances. This example shows that not only background cross-section, but some anomalous features in it play the important role in pollution state and movement. TES is the main method for such pollution study.

Town Syzrany is not far from Novokujbishevsk, and oil-refining factory is quite similar. Pollution on the surface is the same or even stronger, but secondary oil deposit is not found yet. Background cross-section is sandy with thin clay layers. We found traces of pollution spreading downward, noticeable on TES method data, but not oil deposits.

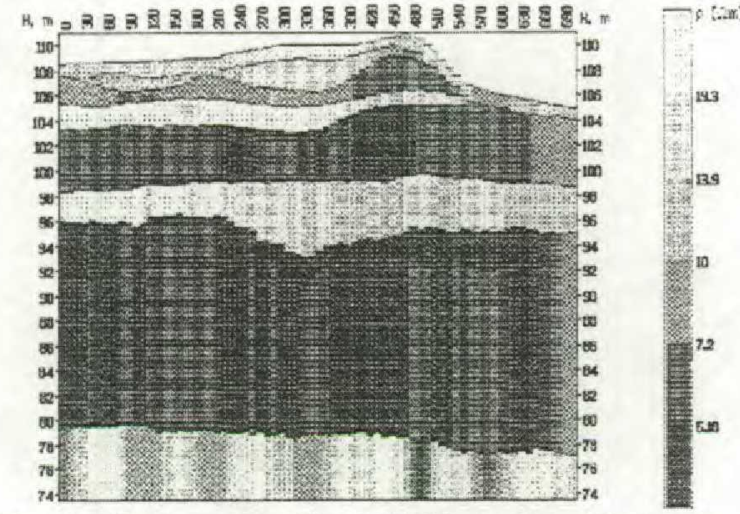

Fig. 12. Syzrany. Profile 4. VES results with traces of oil pollution.

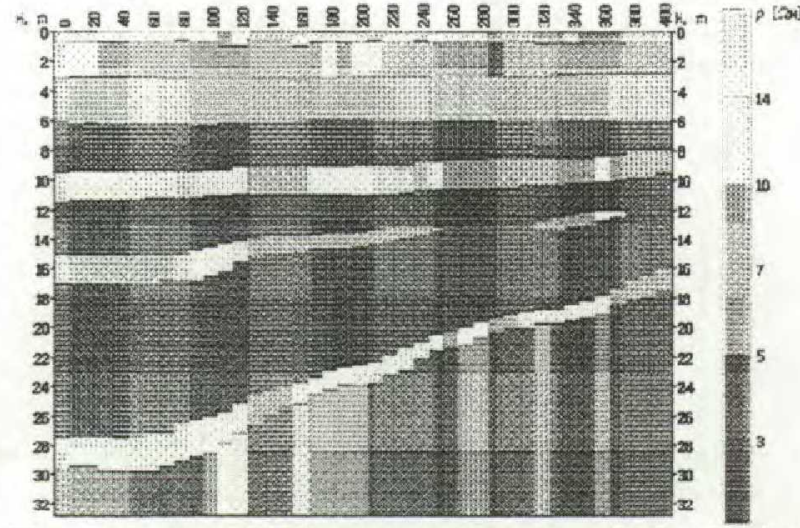

Fig. 13. Syzrany. VES results with traces of oil pollution on profile 2 .

\section{REFERENCES}

1. Bailey N.J.L., Krouse H.R., Evans C.R. Alteration of crude oil by waters and bacteria - evidence from geochemical and isotope studies. American association of petroleum geologist bulletin, N5, 1981.

2. Bailey N.J.L., Jobson A.M., Rogers M.A. Bacterial degradation of crude oil: comparison of field and experimental data. Chemical geology, N11, 1973.

3. Dostalek M. The action of microorganism on petroleum hydrocarbons. Microbiology, 1975.

4. Milner C.W.D., Rogers M.A., Evans C.R. Petroleum transformations in reservoirs. Journal of geochemical exploration, N7, 1977.

5. Vanhala $H$. Mapping oil contaminated sand and till by spectral induced polarization method. EAEG 56 th annual meeting, Zeist, 1994.

6. Vanhala H. Mapping oil contaminated sand and till with the spectral induced polarization (SIP) method. Geophysical Prospecting. 1997, Vol.45, No. 2, p.303-326.

7. I.N.Modin, V.A.Shevnin. A.A.Bobatchev, D.K.Bolshakov, A.A.Gorbunov. Investigations of oil pollution, caused by oil-industrial plants with electrical prospecting methods. Annales Geophysicai. European Geophysical Society. Part 1. Society Symposia, Solid Earth Geophysics \& Natural Hazards. Supplement 1 to Volume 14. P.171. 1996. 